Proceedings

\title{
Intercultural Education against Building Walls. Educational Possibilities from Picturebooks for Children and Teenagers ${ }^{\dagger}$
}

\author{
Mariangela Giusti \\ Department of Human Sciences for Education, University of Milan Bicocca, 20126 Milan, Italy; \\ mariangela.giusti@unimib.it or mari.giusti@gmail.com; Tel.: +39-342-8919-558 \\ + Presented at the International and Interdisciplinary Conference IMAGINI? Image and Immagination \\ between Representation, Communication, Education and Psychology, Brixen, Italy, 27-28 November 2017.
}

Published: 16 November 2017

\begin{abstract}
For understanding some basis concepts of intercultural education, teachers and educators can use with good results the picturebooks on intercultural themes. They allow shared reading of the stories and vision and commentary of the images. The picturebooks with intercultural contents are a novelty in the last years in publishing; so they are an innovative possibility for intercultural education. In this paper some picturebooks will be examined in order to introduce themes of intercultural education in secondary and primary schools. Reading texts and the images suitable for students of different ages can initiate educational dialogues and inner reflections in the students.
\end{abstract}

Keywords: picturebooks; intercultural education; visual narration; literature for children; intercultural learning (Topic 2. Image and imagination in education. Educating and telling)

\section{Introduction}

Several European publishing houses have published picturebooks suitable for the different ages of pupils and students. They are very effective at the didactic level; they face complex issues such as identity, relationship with others, migrations, boundaries, consequences of the wars. The picturebooks are suitable for activating educational situations in which the aloud reading of the story accompanies the vision of images. The teacher and the groups of students are tempted to question, to amaze, to indignate together, to excite, to know. In addition, in the multiethnic classrooms of the Italian educational system not always all students have a good competence in using the Italian language. Therefore, picturebooks allow everyone (through illustrations) to know aspects of the multicultural reality in which children live (natives and migrants). To the students with different mother tongue the picturebooks allow the Italian language to be enhanced as a second language. The reading of the texts and the vision of the images of picturebooks can start up short collective dialogues and some personal reflections. This paper stems from a research conducted in 2015 and 2016 in several primary and secondary schools in Lombardia and Piemonte, two regions of northern Italy, with the collaboration of thirty teachers. In the paper we will examine some picturebooks published in the last three years aimed at intercultural thinking. A deeper discussion is contained in [1] (pp. 93-117).

\section{Intercultural Education and Active Didactics}

Current and future societies are and will be multicultural and multilingual [2] (3-22). The same is true (and will be) in the European and Italian educational systems. In such contexts, intercultural education plays an important role: students learn to attribute value to knowledge related to tradition 
and new knowledge; to local traditions, but also to the traditions of other countries in the world. Intercultural education accustomed children to attributing value to beliefs, symbols, and norms rooted in the territories where migratory human groups have lived for some years in their existence (countries of emigration); but the principles of intercultural education believe that should be valued and not overwhelmed the beliefs, the symbols, the rules rooted in the territories where those migration paths are concluded (countries of arrival). The theoretical perspective of intercultural thinking in education enhances and conveys the idea of connection, a programmatic and methodological idea to decline and transfer to educational and didactic choices in all school orders. The intercultural competence of teachers is related to many aspects of the profession [3] (45-52). Here we cannot go into this topic, but it is important to remember that teachers have to make a first pedagogical step, that is, to well observe and to know the cultural and linguistic variety of the students of the class they are responsible for. Only in this way they can make the right methodological, relational and content choices, appropriate to that specific group of students with those specific cultural, linguistic and religious differences (and not with a generic diversity). Loud reading is a very useful activity, especially when accompanied with image observation. Written texts and illustrations allow you to excite, be amazed, and indignate together (teacher and students) and learn about aspects of the multicultural reality in which they all live. Through narrated stories accompanied by images, boys can find similarities between places, between people, between different times; they can know the feelings, the emotions, and the moods as they were told by narrators and illustrators.

\section{Examples of Picturebooks for Intercultural Teaching}

The picturebooks represent a privileged ground at school for understanding the transformations of society and the experiences of migrations in the present world. The opportunities of picturebooks are significant because they allow students natives and immigrants to know many situations in which the lives of all are involved. It is not easy in fact to teach to twelve or sixteen-year-olds young people that the contact areas between humans, nations, cultures, regions are reality for all the people, not some exceptional situations involving only few persons or some families. Didactic activities using picturebooks can move the self-reflection, the introspection, and the culture of the memory. All this should increase the ability of young people to cultivate good relationships, in classroom, in school and, subsequently, in society. The stories and the described and illustrated experiences allow teachers to start from descriptions that bring so much undesirable data on the surface, acquire new visions and awareness, and help create the collective memory needed in multiethnic classes.

From a methodological point of view, it has emerged from the research that it is necessary to encourage the active use of the picturebooks by the students. The ideal idea is to put one or more picturebooks into the center of well-designed didactic activities, with a meeting schedule prepared by the teacher and well known by the students. These activities must become a time/school opportunity where each one, for the part that compels them, contributes to developing a conscious and civil community.

Ethnic landscapes and the reality of migrations of present years are very complex for adults as well [4]. However, picturebooks for children and teenagers tell at least a small part of this complex reality, honestly and with the reach of children, with illustrations from different styles and with different languages. The writers and illustrators propose direct and competent looks; they tell stories of children and girls traveling alone or mixed in groups of adults, involved in long migrations between different cities and worlds. Some of these stories seem fairy-tale, but instead they report accurately what is happening in the reality of life [5]. Sometimes they talk about travels of long distances from distant countries. This sense effect derived from the illustrated narrative structures can make it possible to "make familiar what is not familiar" [6] (253). The stories in various picturebooks relate to real facts, sometimes occurring to the protagonist (hence, described in autobiographical style), sometimes occurring to other members of the family or to friends or acquaintances. They make the boys understand so many reciprocal exchanges of experiences and 
human relationships. They achieve goals that are related to different disciplinary areas (the geo-historical area; the linguistic-expressive area; the social studies area, for example), but also the growth of the boys themselves. Intercultural education is not just about the cognitive sphere, but it also involves emotional intelligence and identity and human growth.

Below we provide some types of picturebooks usable in school. The short selection proposed represents an initial model by which to teach teachers and educators how to move independently into further documentation and choices.

The learning opportunities provided by the picturebooks are in fact many, but the first essential thing is that teachers know the picturebooks themselves, so they recognize and understand their value. Only if teachers know them, they can be able to offer them to students as real learning tools in the intercultural field.

\subsection{Decentralization: Overcoming the Spaces in Order to Meet Each Other}

Some picturebooks (to be chosen according to the different students' ages) make it possible to let children know other countries and distant worlds, environments and unknown situations. They are picturebooks that activate their curiosity and interest in going beyond the usual spaces. They are tools that encourage children and young people to decentralize, an important exercise to educate them to the intercultural thought. To educate the intercultural comparison means to increase the ability to deploy from the unique point of view and to learn to consider its own way of thinking not the only one possible. Decentralization is a methodological principle in intercultural education and a way to offer it to students is to do so through picturebooks. For upper secondary school students, we give three examples.

The first is an illustrated book to be used in interdisciplinary teaching activities between the French teacher and the Italian teacher who addresses many issues of current societies linked to migration of refugees and asylum seekers: S. Lamoureux, A. Fontaine, Planète Migrants (Actes Sud Junior, Arles, 2016). The written text section is very accurate and documents many aspects of the current situation of millions of refugees in so many parts of the world. The text is very wide but the illustrations have a strong hold on young readers (Figure 1). They are minimalistic designs.

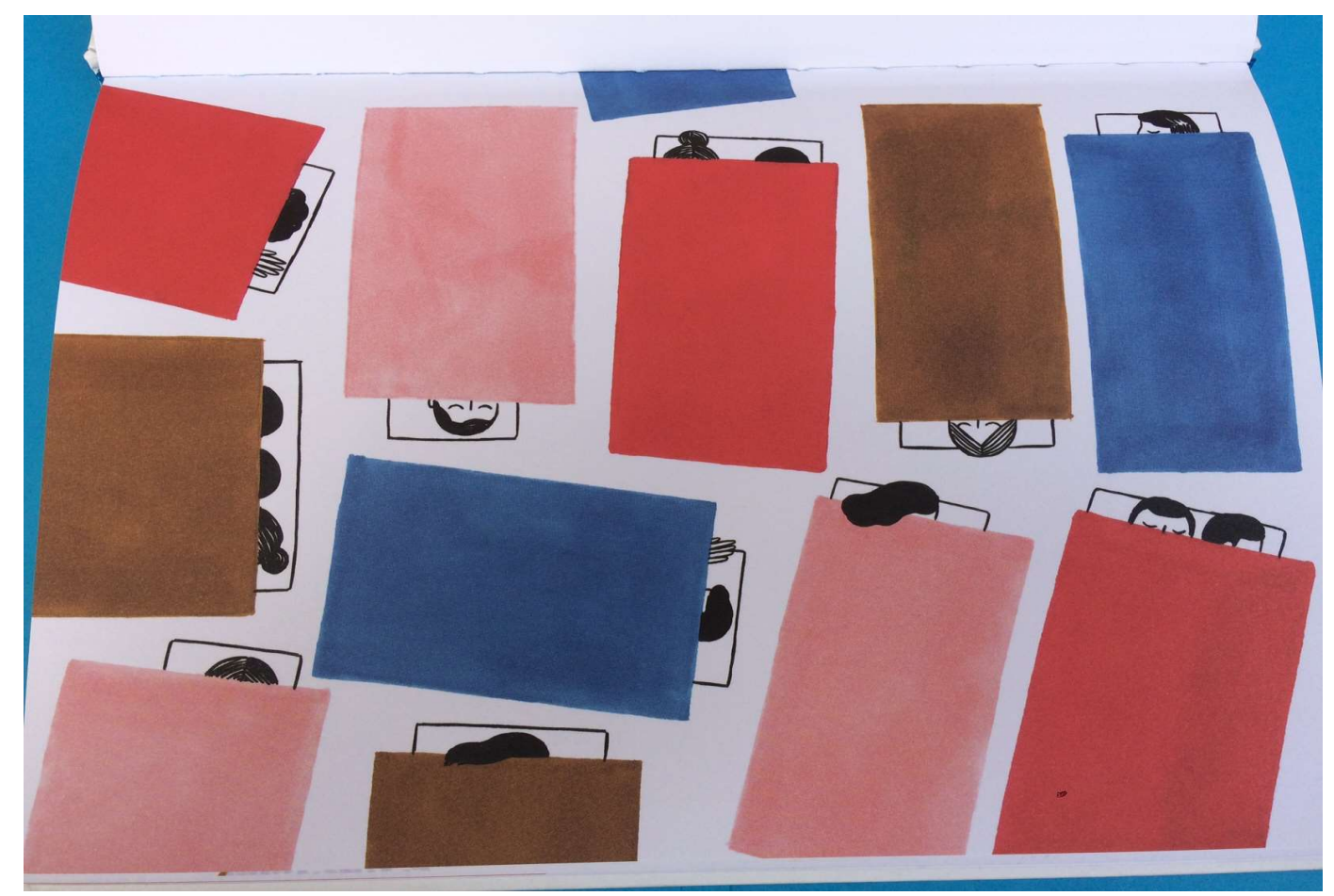

Figure 1. Migrants sleeping in a refugee camp, by: PlanètMigrants, cit. p. 15. 
Impressive in style and colors, showing humanity made of men and women, boys and old persons ready to risk life on lucky boats and live in refugee camps for weeks and months to escape the war or hunger or famine. We adults get realistic and quantitative information from newspapers and television news about the thousands of humans who, after grueling trips, are stopped at the borders, but for the kids the data provided by the newspapers are far away. This illustrated book instead provides a strong picture of the current migration situation in the world that teenagers can understand. In particular, we found references to frequent attitudes of non-acceptance or rejection of migrants (Figure 2).

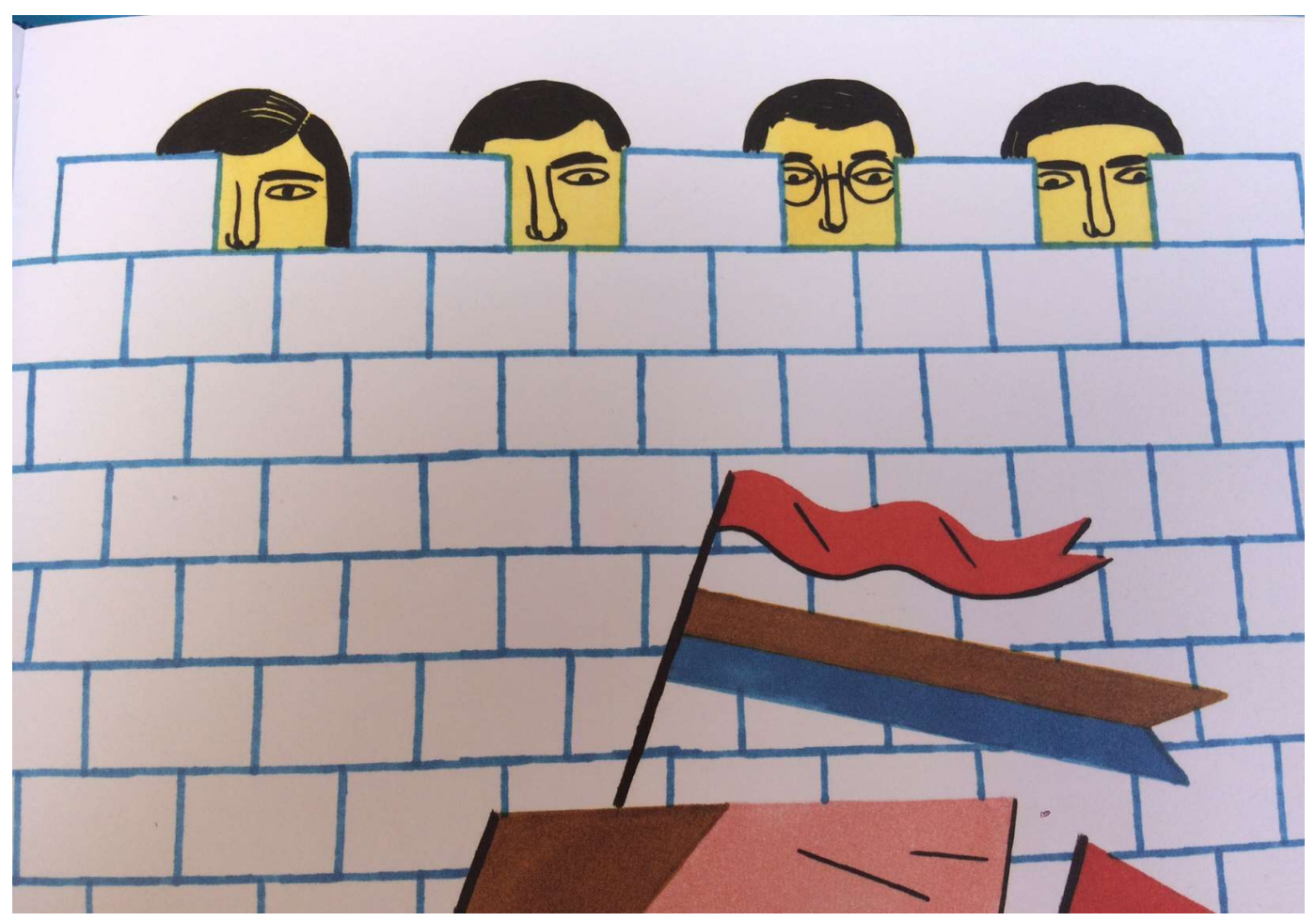

Figure 2. Old or new walls, by: Planète Migrants, cit. p. 39.

The second is a mostly illustrated book, with few written texts: S. Mattiangeli, C. Sitja Rubio, Gli altri (Topipittori, Verona, 2014). The pages of the book (of big dimension) are completely occupied by the illustrations; written texts do not tell a story (with a beginning, a run, and an end), but induce young readers to observe the reality of the streets, squares and sidewalks of the cities where they live, to reflect on the relationships between us and the others (Figure 3). Despite the prevalence of images and color, short texts provide teachers with a good starting material for conducting conversations and educational dialogues with students. But those texts would not have the same force to provoke the thought if there were no images. The picturebook Gli altri can be interpreted as a philosophical book because it causes readers to cognitive shift: the " $\mathrm{I}$ " of the reader-teenager extends towards the "Others" present in the beautiful watercolors of the picturebook. The reader makes room to he Others (told by the texts and the images) that move in the same spaces of the towns inhabited by those who read. It is a very useful book because it allows for cognitive transmutation, a shift of the horizon.

The third picturebook we propose tells the story of a refugee arriving on a beach: A. Greder, L'Isola, (Orecchio Acerbo, Rome, 2014). The text and the illustrations result in a misguided view of the reader; lead to the extreme consequences of a situation; give rise to a divergent thought. The pages of the book, of big dimension, are largely depicted by the illustrations, all played on the tones of gray, brown and black. The texts are short, essential, paratatic. The story told by L'Isola is minimal but very touching: it shows a refugee arriving on an island, received with hostility and suspicion by the inhabitants (Figure 4). The picturebook, with its disturbing illustrations, allows to talk to students of high schools of experiences that characterize the affairs of so many human beings: travel, 
exile, seeking a better place to live, self-recognition, difficult moves, trials, transfer, rejection, return. It is a story that teenagers can understand as a characteristic of the human condition, which make sense through the narrative and figurative re-elaboration that the book proposes.

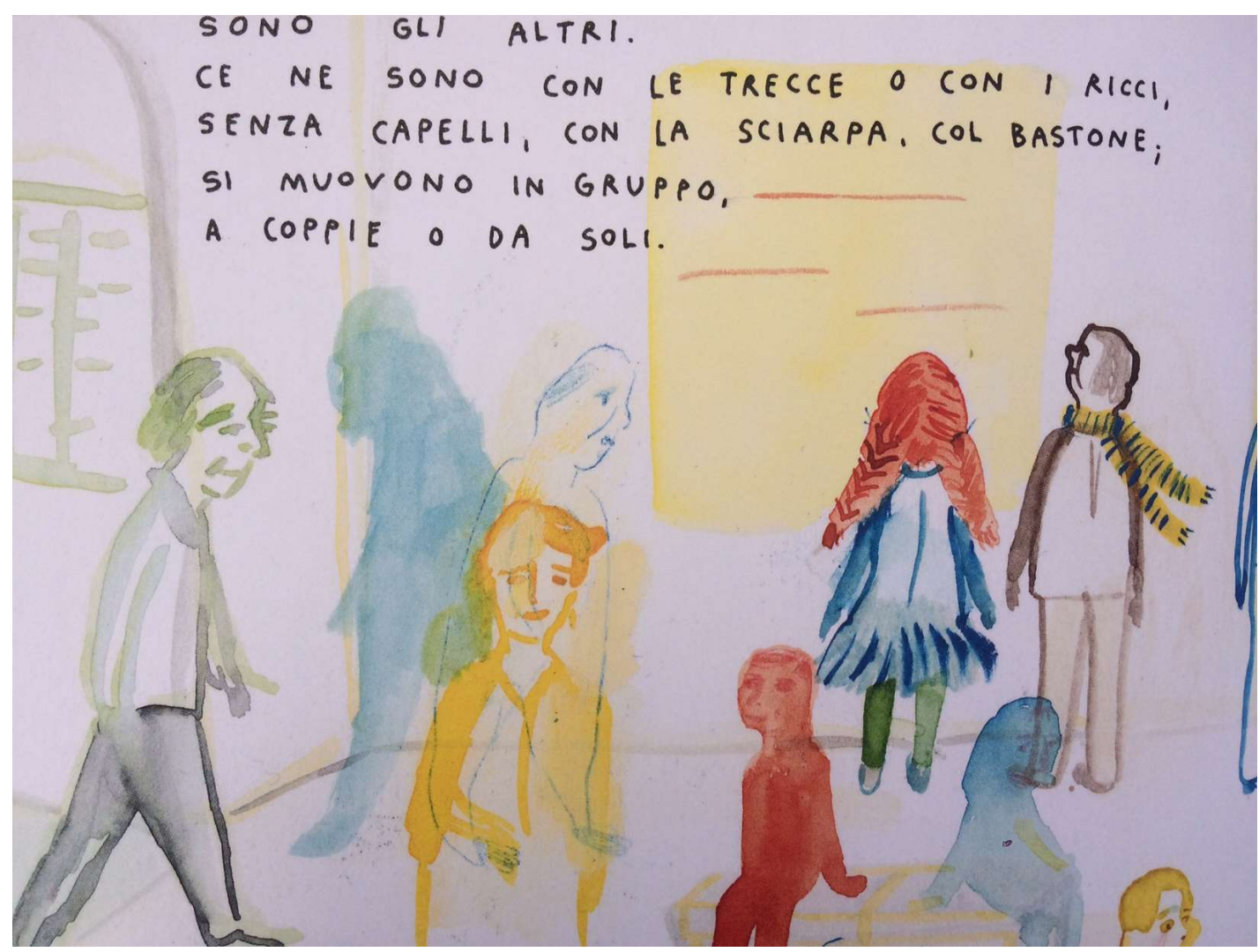

Figura 3. Image of the streets, by: Gli altri, cit. p. 4.

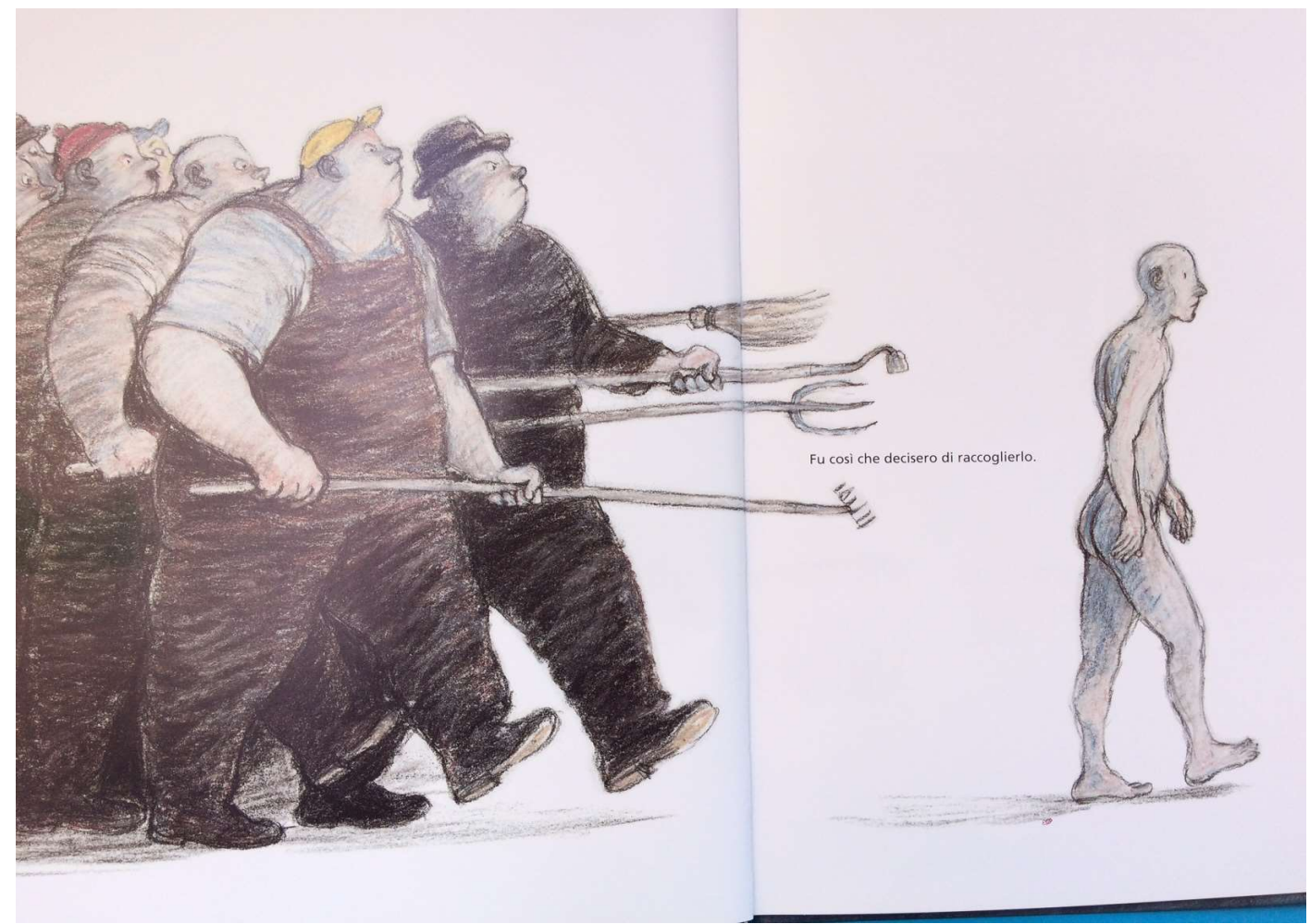

Figure 4. The inhabitants of the island hunt the refugee, by: L'Isola, cit. pp. 8-9. 


\subsection{The Knowledge of Migration Stories}

In other cases, the picturebooks for intercultural education are suitable for creating situations of encounter and sharing between life events that relate to current migrations, with textual language and images that are understandable also by children of primary and middle school. They contribute to create empathy and friendships between native pupils and newcomers from distant countries. Empathic experience has an important role in intercultural education: it represents a bridge to the Other and allows you to know yourself. Various picturebooks address these issues and are suitable for fourth and fifth grade students and of the middle school.

The first album we present use almost exclusively big images to tell the story, a sad and engaging one with very short textes: I. Straw, S. Possentini, Il sogno di Youssef (Camelozampa, Padova, 2016). It is a story (simultaneously real and imaginary) of migration of a child who does not have the desired result. The book is very particular because it is inspired by images widespread a few months ago by televisions all over the world and the newspapers they talked about (and unfortunately tell) the drama of the little children of the boats that do not make it overcome the crossing and die of cold, of starvation, hunger. With illustrations suitable for the age of little readers, it is proposed, for example, the image of a baby lying on a beach, just apparently asleep. The book begins and tells with pictures of a child experiencing loneliness, nostalgia, distance, broken friendships, wounds caused by migrations (Figure 5). The images of the book involve the minds of the children, the feelings, the emotions, the deep values of each one.

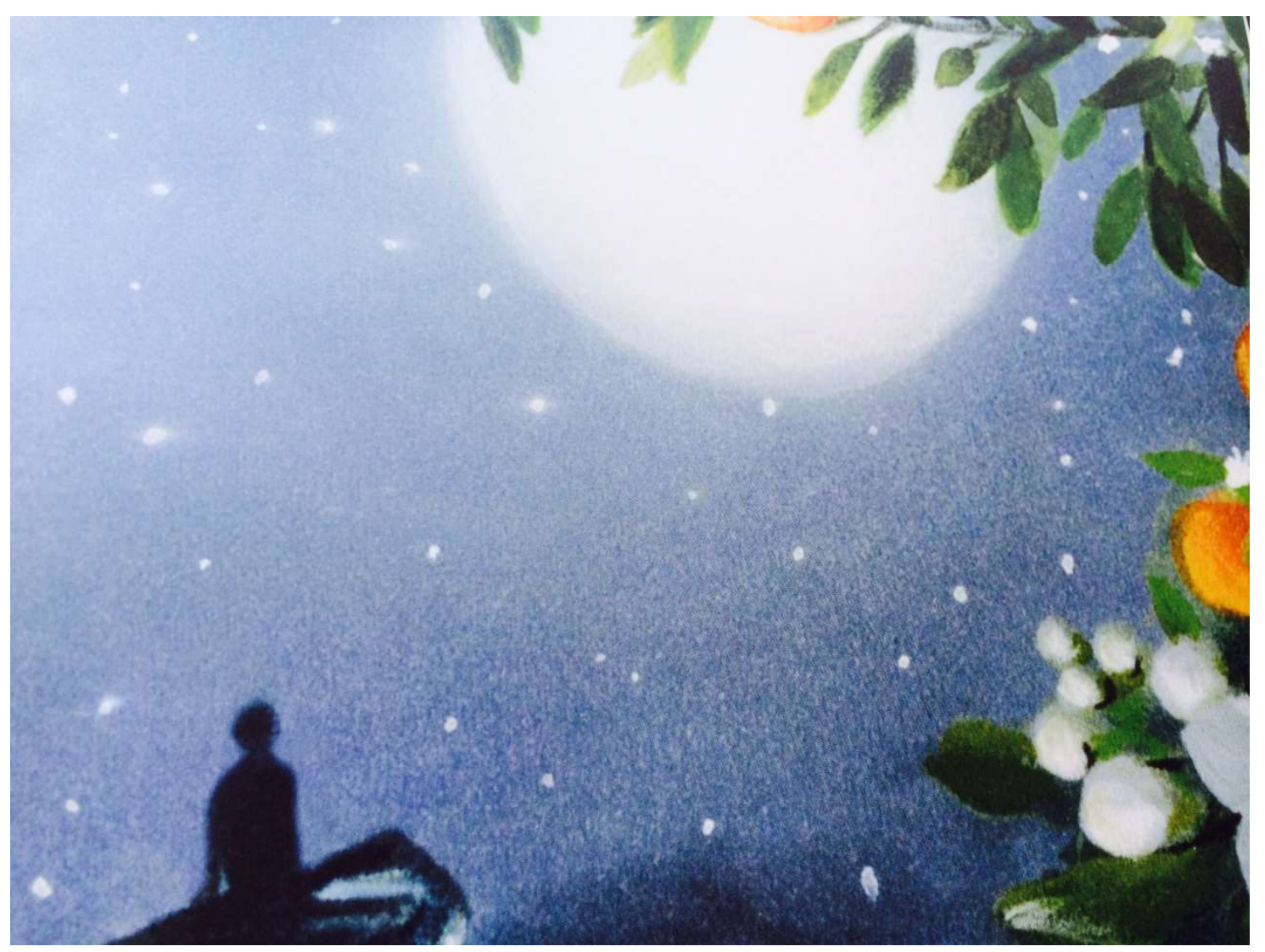

Figure 5. Youssef dived into the sea, by: Il sogno di Youssef, cit. p. 23.

Another beautifully picturebook, full of great ideas both on the textual level and on the illustrations, is: F. Sanna, Il Viaggio (Emme edizioni, Trieste 2016). The story begins with a country in war (maybe the Syria) and tells the journey full of the unknowns, dangers and risks of a young mother who decides to leave with her two children to seek the salvation of a new life in a country of North Europe (perhaps Sweden). The story start with the autobiographical voice: is a little girl who tells her story: "I and my family live in a town near the sea. Every summer at weekends we enjoyed going to 
the beach. But now we do not go anymore because last year our life has changed forever. The war started" (Sanna, p. 2). From here begins the dramatic adventure of escaping a mother with two children with the goal of reaching a country full of mountains up to that point only known on the pages of the books. The long path (at the beginning it is a journey, then it becomes a getaway) it poses risks and dangers of all kinds. At some point, the desperate journey must stop because the lady and the two children are facing a high wall (Figure 6), a border that is impossible to overcome.

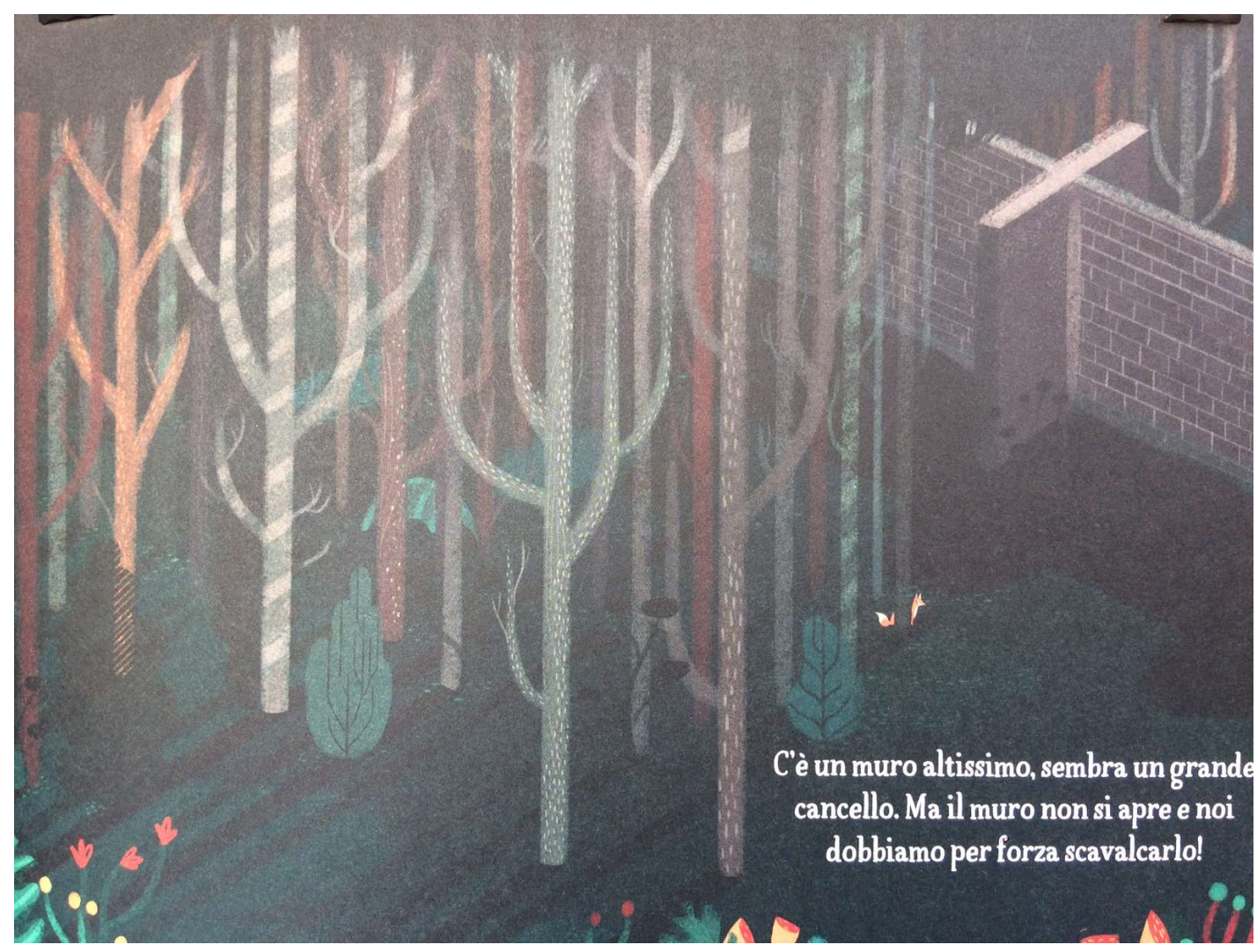

Figure 6. The wall, from: Il Viaggio, cit. p. 21.

Other three picturebooks are significant because they do not underestimate the problems of current migrations but only make it comprehensible by children and teenagers. Each picturebook of this group allows for various activities of dialogue, knowledge, empathic reading, and writing. They report, with simple stories and significant images, various experiences that characterize the affairs of human beings in migration: journey, exile, friendship, difficult travel, trials, transfer, return, and family life. There are stories that kids can understand as a characteristic of the human condition and that they gain meaning through their narrative reworking and images. The first two are books composed of short novels: AA.VV., Sogni al di là del mare (Mammeonline editore, Foggia, 2016); AA.VV., A braccia aperte. Storie di bambini migranti (Mondadori, Milano, 2016). The third tells a crossing of migration of the Mediterranean Sea from the point of view of animals (a dog, a cat, a kid, an eagle) traveling on the boat alone or with their masters: M. Rizzo, L. Bonaccorso, L'immigrazione spiegata ai bambini. Il viaggio di Amal (Becco Giallo, Padova, 2016). This last book shows a very nice illustration (Figure 7) with the image of the rescue of a group of refugees at sea. 


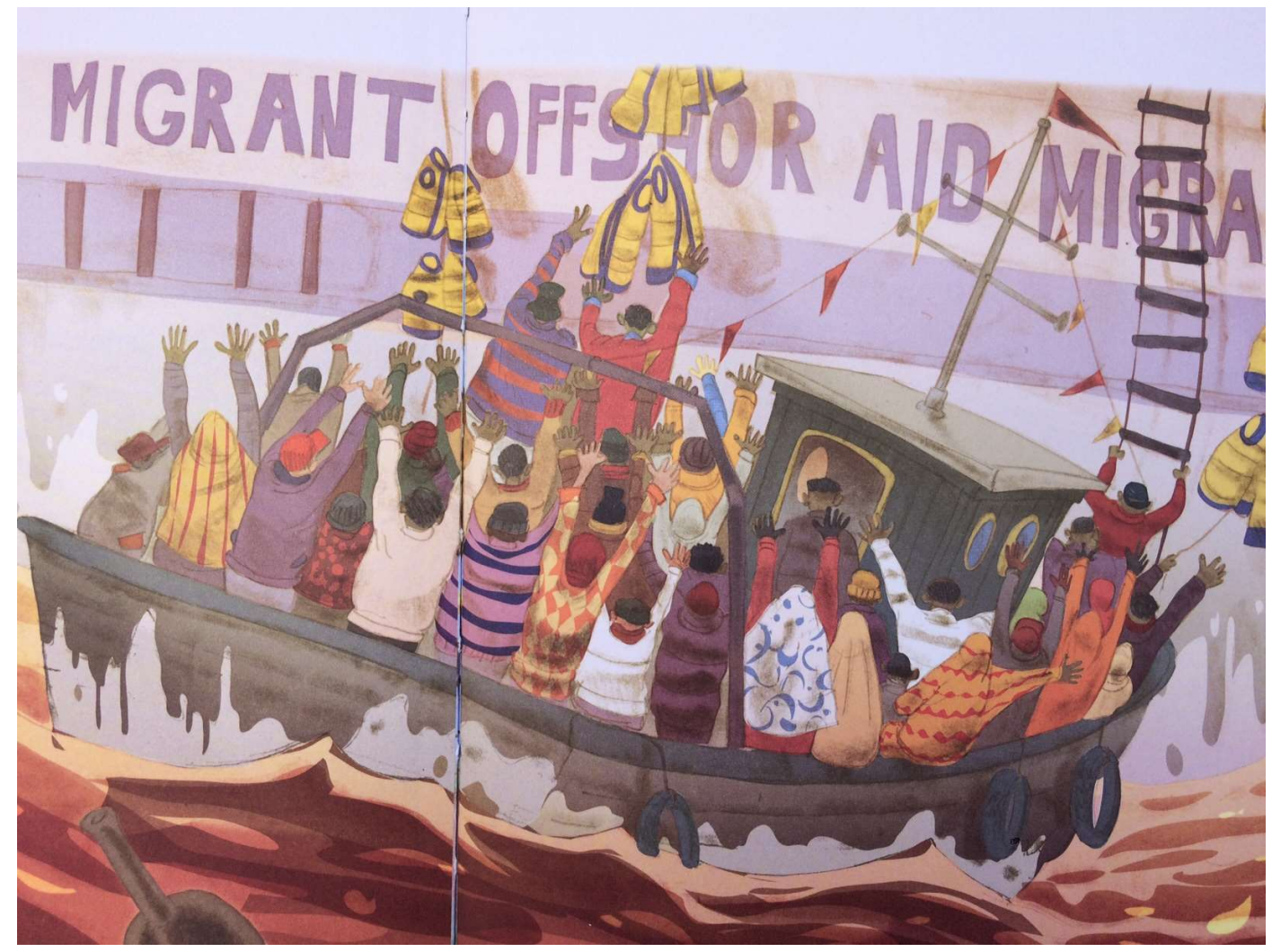

Figure 7. Rescue of refugees, by: L'immigrazione spiegata ai bambini, cit. p. 44.

\section{Methodological Indications for the Didactic use of Picturebooks}

If we want the intercultural teaching activities to have a good educational impact, we must use the picturebooks regularly, not sporadically. These activities should have at least two purposes:

- to convey to children the idea that each one's culture is the result of encounters, exchanges and interweaving between the tradition of the group to which it belongs and the traditions of other groups;

- to make clear to the boys that each person retains an heritage (in many respects common to the human group to which he belongs or to the family of which he is part) that includes knowledge, beliefs, fantasies, ideologies, symbols, norms, values to which continually adding more.

If the activity takes place in the classroom, teachers should foresee some passages: collective reading aloud, observations of images, passages of books from the hands of boys, listening and viewing, passage of words, and solicitation to dialogue. If there is the possibility, one can expect to add to the reading and reflection the direct encounter with one or more adults, to be invited in the classroom to collect from their voice stories of experiences lived, similar to those read. With older students, reading the picturebook can be the beginning to know people who have experienced the migration.

Some methodological indications to be taken into account in project of the classroom activities in which the picturebooks are used are as follows.

1. It is important to pay attention to the choice of the picturebook (or picturebooks if you decide to use more than one) as it must be suitable for the pupils age.

2. It is advisable to devote a defined time to: reading, listening, observing the illustrations in the classroom; this means it should not be a residual time. For example, not in the last fifteen minutes of the morning, nor in the middle of other activities those students perceive as "the most important." The teacher has to schedule a didactic time in the daily (or weekly, or monthly calendar of activities) so that the pupils perceive the use of picturebooks as a significant activity. 
3. It is good to identify the best room arrangement for the students and the teacher, who must be close; the school benches can be left in place or you can choose to place them at the bottom of the classroom and sit in a circle. The picturebooks must be able to easily go hand in hand, be seen and appreciated.

4. Those who start reading (teacher or educator) must devise the voice setting that must be clear and not distorted in the shades; he must take care of the correct pronunciation of the words. Educational lessons whit picturebooks and narrative reading on migration issues represent significant moments for not Italian speakers students, for better acquisition of the Italian L2.

5. It is good to propose some breaks. This allows children to internalize language, images and content and the adult (teacher or educator) to grasp and respect the reactions they notice in students (boredom, fun, emotion, lack of understanding, uncertainty, etc.).

6. It is advisable to alternate the imaginative and narrative function with the documentary of the narrated word and the images, making connections with small or big events of the chronicle. This makes various cognitive functions active.

\section{An Example of Picturebook for High School Teenagers}

Armin Greder, author of the text and of illustrations of the picturebook L'isola (Figure 8) in many ways has prophetical anticipated the difficulties and the contradictions of current migrations (the book in fact came out in first edition in Germany in 2002). The stylistic choice of Greder seems to be very well-known: is based on the amplification of meanings, dialogues and images through the use (both in the lexicon and illustrations) of the hyperbole. In this way, L'isola brings to the excess the actions of the characters, it shows young readers that the story they have in their hands is an exaggeration, an exasperation of reality, and therefore it is not to be imitated. Here, then, the story told and illustrated becomes a pedagogical tool. It passes some correct ethical choices and some points of view on the world that will then come to the boys (each of them, with a process of interiorization that is all individual, not of group) welcome and do their own, without forcing by the teacher. In other words, it is the hyperbole itself to leverage to disrupt prejudices (or to avoid creating oneself) in the young consciousness in formation. Teachers (or educators) can use a picturebook like L'isola to start dialogues with teenagers on migration trips, starting from questions/stimulus based on the images and the story told. For example: what could have been the cause of the protagonist's journey of history? Poverty, war, famine? Do you know people or boys who have been emigrating from their countries? Do you know some details of their stories that struck you? When they arrived, in what way were they greeted? Which countries or places can you think by watching the pictures and reading the story of L'isola? Do you think it happens in the reality that a group of people reject a refugee in the sea? Really do you think that building a high wall to protect an island could be a solution to the great migrations of our day? Let's make the picturebook helps connect with national chronicle situations and micro-chronicles of the various areas where the teenagers live. Let's ensure that the picturebook helps to create attention of teenagers towards the stories of those who live in their city or in the suburbs: the neighbor coming from Eastern Europe, a girl native from Africa known in the Church; a classmate who does not speak Italian coming from China, etc. If we see that students understand the meaning of the L'isola, we can introduce the concept of "fear": in your opinion, who seems to be more frightened: the island's inhabitants or the refugee? Why so?

\section{Conclusions}

The use of picturebooks helps to design educational activities that go in the direction of increasing cohesion in class groups, motivation, good educational relationship, knowledge transfer and skills in the use of the Italian language. Class groups are characterized (and increasingly will be) by a strong linguistic and cultural heterogeneity; picturebooks can help teachers design their educational proposals based on the characteristics of students, their skills, and their interests. Among the principles of the intercultural education set out some years ago by the Council of Europe there is the enhancement of the plurality of views and languages spoken; the picturebooks are 
instruments that go in this direction. They promote mutual language learning as they facilitate listening, speaking, sharing, reading, talking between teachers and members of the learning group. The picturebooks as well as some wordlessbooks (as an example: S. Tan, L'approdo, Elliot, Roma, 2008, originally published by Lothian Children Books, Australia, 2006) put teacher and students in front of a wide variety of models and life projects, relationship modes, migrations and travels. They are great tools to create in the classroom, at school, good contexts of comparison that will fit into respect for the origins, languages, habits, family traditions, religions, and spiritual worlds of all people.

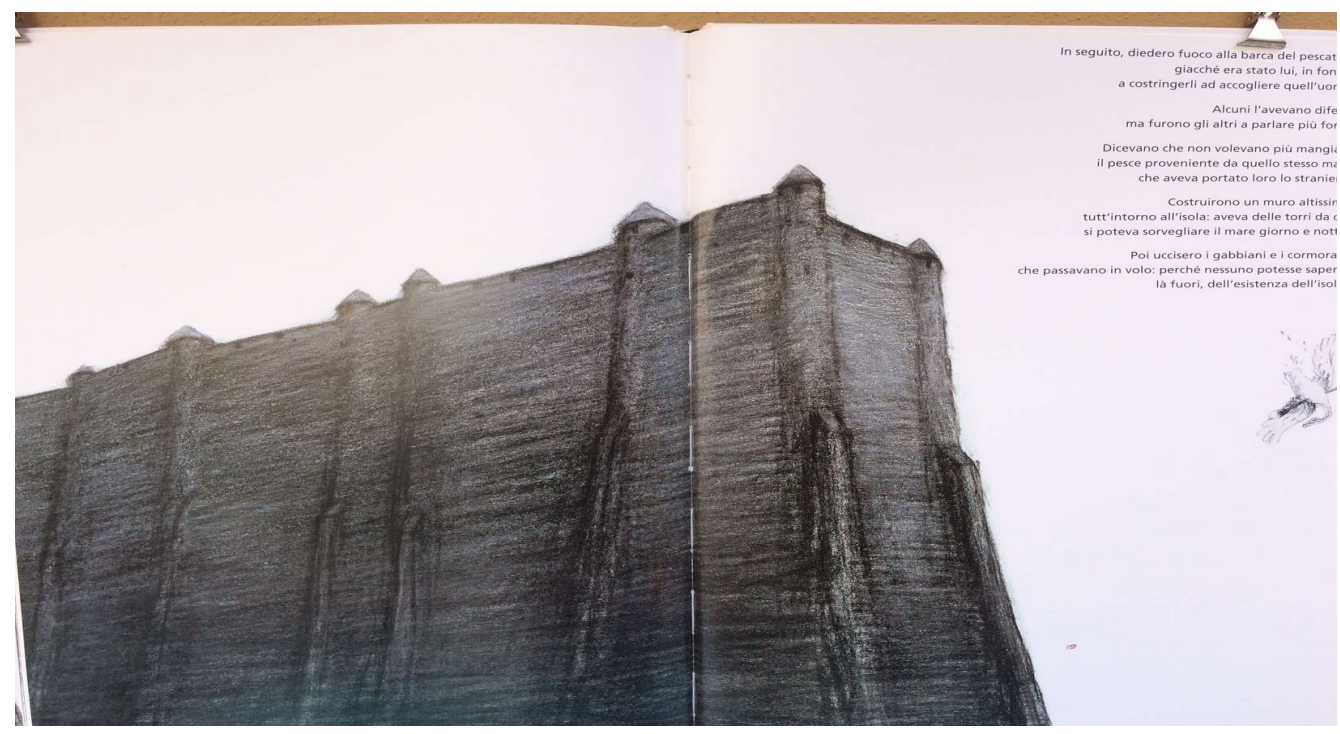

Figure 8. The construction of the wall, from: L'isola, cit. pp. 28-29.

Conflicts of Interest: The authors declare no conflict of interest.

\section{References}

1. Giusti, M. Teorie e Metodi di Pedagogia Interculturale; Laterza: Roma Bari, Italy, 2017; ISBN 978-88-593-00397.

2. Bauman, Z. Liquid Modern Challenges to Education. In Intercultural Education and Competences; Portera, A., Grant, C., Eds.; Cambridge Scolars Publishing: Newcastle, UK, 2017; pp. 3-22, ISBN 9781443821315.

3. Deardorff, D.K. Framework: Intercultural Competence Model. In Building Cultural Competence; Berardo, K., Deardorff, D.K., Eds.; Stylus Publishing: Sterling, VA, USA, 2012; pp. 45-52; ISBN 9781579228040.

4. Ciabarri, L. (Ed.) I Rifugiati e Europa. Tra Crisi Internazionali e Corridoi D'accesso; Edizioni Libreria Cortina: Milano, Italy, 2015; ISBN 9788870431957.

5. Attanasio, L. Il Bagaglio. Migranti Minori Non Accompagnati: Il Fenomeno in Italia, i Numeri, le Storie; Albeggi Edizioni: Roma, Italy, 2016; ISBN 9788898795.

6. Ricoeur, P. Tempo e Racconto; Volume I; Jaca Book: Milano, Italy, 1983; ISBN 8816401656.

(C) 2017 by the authors. Licensee MDPI, Basel, Switzerland. This article is an open access article distributed under the terms and conditions of the Creative Commons Attribution (CC BY) license (http://creativecommons.org/licenses/by/4.0/). 